\title{
Neuroimaging Characteristics of Small-Vessel Disease in Older Adults with Normal Cognition, Mild Cognitive Impairment, and Alzheimer Disease
}

\author{
Alberto Mimenza-Alvarado ${ }^{a}$ Sara G. Aguilar-Navarro ${ }^{a}$ \\ Sara Yeverino-Castro ${ }^{a}$ César Mendoza-Franco ${ }^{a}$ \\ José Alberto Ávila-Funes ${ }^{a}$ c Gustavo C. Román ${ }^{b}$ \\ ${ }^{a}$ Department of Geriatric Medicine, Instituto Nacional de Ciencias Médicas y Nutrición

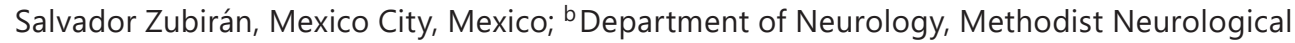 \\ Institute, Houston Methodist Hospital, Houston, TX, USA; ' University of Bordeaux, Inserm, \\ Bordeaux Population Health Research Center, UMR 1219, Bordeaux, France
}

\section{Keywords}

Alzheimer disease $\cdot$ Mild cognitive impairment $\cdot$ Small-vessel disease

\begin{abstract}
Introduction: Cerebral small-vessel disease (SVD) represents the most frequent type of vascular brain lesions, often coexisting with Alzheimer disease (AD). By quantifying white matter hyperintensities (WMH) and hippocampal and parietal atrophy, we aimed to describe the prevalence and severity of SVD among older adults with normal cognition (NC), mild cognitive impairment $(\mathrm{MCl})$, and probable $A D$ and to describe associated risk factors. Methods: This study included 105 older adults evaluated with magnetic resonance imaging and clinical and neuropsychological tests. We used the Fazekas scale (FS) for quantification of WMH, the Scheltens scale (SS) for hippocampal atrophy, and the Koedam scale (KS) for parietal atrophy. Logistic regression models were performed to determine the association between FS, SS, and KS scores and the presence of NC, $\mathrm{MCl}$, or probable AD. Results: Compared to NC subjects, SVD was more prevalent in $\mathrm{MCl}$ and probable AD subjects. After adjusting for confounding factors, logistic regression showed a positive association between higher scores on the FS and probable AD (OR $=7.6,95 \% \mathrm{Cl} 2.7-20, p<0.001)$. With the use of the SS and KS (OR $=4.5$, $95 \% \mathrm{Cl} 3.5-58, p=0.003$ and $\mathrm{OR}=8.9,95 \% \mathrm{Cl} 1-72, p=0.04$, respectively), the risk also remained significant for probable AD. Conclusions: These results suggest an association between severity of vascular brain lesions and neurodegeneration. @ 2018 The Author(s)


Mimenza-Alvarado et al.: Neuroimaging Characteristics of Small-Vessel Disease in Older Adults with Normal Cognition, Mild Cognitive Impairment, and AD

\section{Introduction}

Alzheimer disease (AD) is the most common type of dementia among older adults. Early deposits of cerebral amyloid-beta and tau protein are distinctive markers of AD, and their histological quantification remains a hallmark for definitive diagnosis [1]. However, cerebral small-vessel disease (SVD) frequently coexists with AD pathology. Recent studies recognize similar vascular risk factors for both SVD and AD [2]. In addition, post-mortem studies demonstrate the presence of vascular lesions in up to $79.9 \%$ of individuals with pathologically confirmed $\mathrm{AD}$ [3], leading to the recognition that pure forms of dementia in the elderly are relatively infrequent.

SVD is a disease that affects small arteries, arterioles, veins, and capillaries of the brain and is considered the most frequent cause of vascular dementia. Recent standardization of SVD lesions on conventional magnetic resonance imaging (MRI) includes small subcortical infarcts, lacunar strokes, white matter hyperintensities (WMH), dilated perivascular spaces, and brain atrophy, allowing the neuroradiological diagnosis of cerebral SVD [4]. The Fazekas scale (FS) [5] is a widely used method to quantify the severity of WMH lesions on T2/FLAIR sequences.

Other than subcortical lesions, SVD also induces atrophy in cortical regions [5]. Routine clinical use of rating scales allows imaging assessment of cerebral atrophy in dementia. The Scheltens scale (SS) [6] is commonly used to measure brain hippocampal atrophy in coronal T1-weighted images, whereas the Koedam scale (KS) [7] enables the visual assessment of parietal atrophy associated with early-onset AD.

Atrophy and WMH are common neuroradiological findings, but few studies have associated these insults with cognition in community-dwelling populations [8]. The extent of WMH has been associated with cognitive impairment. Similarly, a higher risk of developing dementia has been suggested among mild cognitive impairment (MCI) patients with higher SVD burden [9]. By quantifying WMH and hippocampal and parietal atrophy, we aimed to describe the prevalence and severity of SVD among older adults with normal cognition (NC), $\mathrm{MCI}$, and probable AD and to describe associated risk factors.

\section{Materials and Methods}

\section{Participants}

This cross-sectional study was conducted at the Memory Clinic of a tertiary-level University Hospital in Mexico City. A total of 105 older adults aged 60 years or older were consecutively recruited. Each subject completed clinical and neuropsychological evaluations between June 2015 and June 2016. Based on the results of the evaluations, subjects were allocated to 3 different groups: NC, MCI, or AD. For this study, we excluded subjects with major depression, non-AD dementias, other neurological disorders, including structural cerebral lesions that could affect cognitive functions (i.e., acute stroke, brain tumors, or normal pressure hydrocephalus), as well as subjects without available MRI. The local Ethics Committee approved this study.

\section{Neuropsychological Evaluation}

A functional and neuropsychological evaluation was performed in order to establish the subject's cognitive status (dependent variable), including the following tests:

1. Mini-Mental State Examination (MMSE) for the evaluation of global cognition (scores between 24 and 30 were included) [10]. 
Mimenza-Alvarado et al.: Neuroimaging Characteristics of Small-Vessel Disease in Older Adults with Normal Cognition, Mild Cognitive Impairment, and AD

2. Clinical Dementia Rating Scale (score $=0.5$ ) for the evaluation of cognitive and functional performance [11].

3. The Katz Index of Independence in Activities of Daily Living (ADL) and the Lawton Instrumental Activities of Daily Living (IADL) Index were used for the assessment of functional status $[12,13]$. A subject was considered independent for ADL when the score was $\geq 6$ and dependent when the score was $<6$. A subject was considered independent for IADL when the score was $=8$ and dependent when the score was $\leq 7$ for women and $\leq 5$ for men.

4. The brief Neuropsychological Evaluation in Spanish (NEUROPSI) [14] was used for the assessment of specific domains affected differentially in cerebral impairment. The cognitive domains evaluated in various subtests of the NEUROPSI include orientation, attention and concentration, language, memory, executive functions, reading, writing, and calculation.

- MCI diagnosis was established according to Petersen's [15] criteria: (1) memory complaints or increased forgetfulness; (2) memory impairment (according to standardized neuropsychological tests); (3) the cognitive deficits do not interfere with activities of daily living; and (4) absence of dementia diagnosis.

- Dementia diagnosis was established in a 2-step approach: first, a neurologist performed a clinical and neurological evaluation, and second, a neuropsychological evaluation was conducted by an expert neuropsychologist. Diagnostic agreement was established according to DSM-IV criteria [16]. Probable AD diagnosis was based on previously published international criteria [17].

- NC was considered if subjects denied a memory complaint and performed normally in the battery of neuropsychological tests according to age and educational level [18].

\section{Sociodemographic and Clinical Variables}

Information about subjects' age, sex, educational level (in years), body mass index (in $\mathrm{kg} / \mathrm{m}^{2}$ ), history of smoking, alcoholism, presence or absence of traumatic cerebral lesions, and chronic diseases, such as diabetes, hypertension, hypothyroidism, cardiovascular disease, atrial fibrillation, and vascular cerebral diseases was recorded. Depressive symptoms were evaluated with the 15 -item version of the Geriatric Depression Scale (GDS-15); a score $>5$ was considered positive for depressive symptoms [19].

\section{Brain MRI Studies}

All subjects underwent an MRI using a standard protocol. Images were obtained with a 1.5-T Magnetic Resonance Scanner (Siemens ${ }^{\circledR}$ Medical Systems), including whole-brain T2-weighted, T1-weighted, and T2*-weighted gradient-recalled echo, FLAIR, and diffusion sequences. A neuroradiologist performed the MRI assessments blinded to the subjects' clinical information.

\section{Visual Classification}

WMH were evaluated on axial T2-weighted and FLAIR sequences using the FS [5] and classified according to the following stages: 0 (absence of lesions), 1 (nonconfluent lesions), 2 (confluent lesions), and 3 (diffuse lesions). The degree of medial temporal atrophy was rated on T1-weighted images according to the SS [6] as follows: 0 (no atrophy), 1 (mild atrophy), 2 (mild/moderate atrophy), 3 (moderate/marked atrophy), and 4 (marked atrophy). Parietal atrophy was assessed on T1-weighted images with the use of the KS [7] consisting of 4 stages: 0 (no atrophy), 1 (mild atrophy), 2 (moderate atrophy), and 3 (severe atrophy). Cerebral microbleeds were evaluated on $\mathrm{T} 2 *$-weighted gradient sequences with a dichotomized classification according to presence or absence. 
Table 1. Sociodemographic characteristics, cardiovascular risk factors, and cognitive performance in NC, $\mathrm{MCI}$, and probable AD subjects

\begin{tabular}{lcccr}
\hline & NC $(n=34)$ & MCI $(n=41)$ & Probable AD $(n=30)$ & $p$ \\
\hline Age, years & $70 \pm 6.8^{\mathrm{A}, \mathrm{C}}$ & $75 \pm 5.8^{\mathrm{B}, \mathrm{C}}$ & $80 \pm 8.3^{\mathrm{A}, \mathrm{B}}$ & $<0.001$ \\
Female & $24(70)$ & $22(53)^{\mathrm{B}}$ & $23(76)^{\mathrm{B}}$ & 0.100 \\
Education, years & $12 \pm 5^{\mathrm{A}}$ & $10 \pm 7.3^{\mathrm{B}}$ & $3 \pm 3.8^{\mathrm{A}, \mathrm{B}}$ & $<0.001$ \\
Body mass index & $26 \pm 3.8^{\mathrm{A}}$ & $25 \pm 3.7^{\mathrm{B}}$ & $23 \pm 4.2^{\mathrm{A}, \mathrm{B}}$ & 0.072 \\
\hline Type 2 diabetes & $3(8)^{\mathrm{A}, \mathrm{C}}$ & $18(43)^{\mathrm{C}}$ & $10(33)^{\mathrm{A}}$ & 0.002 \\
Hypertension & $13(38)^{\mathrm{C}}$ & $25(61)^{\mathrm{C}}$ & $16(53)$ & 0.045 \\
Dyslipidemia & $13(38)^{\mathrm{A}}$ & $14(35)^{\mathrm{B}}$ & $23(76)^{\mathrm{A}, \mathrm{B}}$ & $<0.001$ \\
Smoking status, yes & $12(35)^{\mathrm{A}}$ & $20(48)^{\mathrm{B}}$ & $23(76)^{\mathrm{A}, \mathrm{B}}$ & $<0.001$ \\
\hline GDS & $2 \pm 2.2^{\mathrm{A}}$ & $3 \pm 2.7$ & $3 \pm 2.9^{\mathrm{A}}$ & 0.035 \\
Katz & $5 \pm 0.3^{\mathrm{A}}$ & $5 \pm 0.41^{\mathrm{B}}$ & $4 \pm 1.5^{\mathrm{A}, \mathrm{B}}$ & $<0.001$ \\
Lawton & $7 \pm 0.3^{\mathrm{A}, \mathrm{C}}$ & $6 \pm 1.4^{\mathrm{B}, \mathrm{C}}$ & $2 \pm 2.0^{\mathrm{A}, \mathrm{B}}$ & $<0.001$ \\
MMSE & $29 \pm 0.91^{\mathrm{A}}$ & $27 \pm 4.2^{\mathrm{B}}$ & $14 \pm 5.6^{\mathrm{A}, \mathrm{B}}$ & $<0.001$ \\
\hline NEUROPSI & & & & $<0.001$ \\
$\quad$ Orientation & $6 \pm 0^{\mathrm{A}}$ & $6 \pm 0^{\mathrm{B}}$ & $4.57 \pm 1$ & $<0.001$ \\
$\quad$ Attention & $20.7 \pm 3^{\mathrm{A}, \mathrm{C}}$ & $16.5 \pm 4^{\mathrm{B}}$ & $12.5 \pm 4$ & $<0.001$ \\
$\quad$ Memory & $40.6 \pm 4^{\mathrm{A}, \mathrm{C}}$ & $34.1 \pm 7^{\mathrm{B}}$ & $20.3 \pm 3$ & $<0.001$ \\
$\quad$ Language & $23.2 \pm 3^{\mathrm{A}, \mathrm{C}}$ & $21.4 \pm 2^{\mathrm{B}}$ & $18.5 \pm 2$ & $<0.001$ \\
$\quad$ Reading and writing & $4.8 \pm 0.5^{\mathrm{A}}$ & $4.7 \pm 2.5^{\mathrm{B}}$ & $2 \pm 2$ & $<0.001$ \\
$\quad$ Executive functions & $15.8 \pm 2^{\mathrm{A}, \mathrm{C}}$ & $13.5 \pm 3^{\mathrm{B}}$ & $8.7 \pm 4$ & 0.052 \\
$\quad$ Visuospatial and visuo- & $12.2 \pm 8$ & $10.6 \pm 2$ & $7.8 \pm 3$ & \\
$\quad$ constructive (copy) abilities & & & \\
\hline
\end{tabular}

Values are means \pm standard deviations or $n(\%)$. NC, normal cognition; MCI, mild cognitive impairment; AD, Alzheimer disease; GDS, Geriatric Depression Scale; Katz, Index of Independence in Activities of Daily Living; Lawton, Instrumental Activities of Daily Living Index; MMSE, Mini-Mental State Examination; NEUROPSI, brief Neuropsychological Evaluation in Spanish. Post-hoc Bonferroni analysis: ${ }^{A}$ AD versus NC, $p<0.05 ;{ }^{\mathrm{B}}$ AD versus MCI, $p<0.05 ;{ }^{\mathrm{C}} \mathrm{MCI}$ versus NC, $p<0.05$.

\section{Statistical Analysis}

Variables were described using arithmetic means, standard deviations, frequencies, and proportions. Categorical variables were compared using the $\chi^{2}$ test. Analysis of variance (ANOVA) and post hoc Bonferroni analysis were used to identify differences between groups. Multivariate logistic regression models were constructed in order to identify the association between the severity in the FS, KS, and SS scoring results and the presence of cognitive impairment, adjusting for age, educational level, and cardiovascular risk factors (diabetes, hypertension, dyslipidemia, and current smoking status). Associations were considered significant at the 0.05 level. Analyses were performed using SPSS version 22 for Windows ${ }^{\circledR}$ (Chicago, IL, USA).

\section{Ethical Issues}

The research protocol was reviewed and approved by the Institutional Review Board at Instituto Nacional de Ciencias Médicas y Nutrición Salvador Zubiran. All study participants signed an informed consent. 
Table 2. Bivariate analysis to demonstrate the differences between the groups according to SMD quantification by the Fazekas, Scheltens (hippocampal atrophy), and Koedam (parietal atrophy) scales on MRI

\begin{tabular}{|c|c|c|c|c|c|}
\hline & Classification & $\begin{array}{l}\text { NC, } n(\%) \\
(n=34)\end{array}$ & $\begin{array}{l}\text { MCI, } n(\%) \\
(n=41)\end{array}$ & $\begin{array}{l}\mathrm{AD}, n(\%) \\
(n=30)\end{array}$ & $p$ \\
\hline \multirow[t]{4}{*}{ Fazekas scale ${ }^{\mathrm{A}-\mathrm{C}}$} & 0 & $16(47.1)$ & $6(14.6)$ & $2(6.7)$ & $<0.001$ \\
\hline & 1 & $15(44.1)$ & $28(68.3)$ & $6(20)$ & \\
\hline & 2 & $3(8.8)$ & 7 (17.3) & $22(73)$ & \\
\hline & 3 & 0 & 0 & 0 & \\
\hline \multirow[t]{5}{*}{ Scheltens scale ${ }^{A-C}$} & 0 & $21(61.8)$ & $18(43.9$ & 0 & $<0.001$ \\
\hline & 1 & $11(3.4)$ & $15(36.6)$ & 5 (16.7) & \\
\hline & 2 & $2(5.9)$ & 7 (17.1) & $13(43.4)$ & \\
\hline & 3 & 0 & $1(2.4)$ & $10(33.3)$ & \\
\hline & 4 & 0 & 0 & $2(6.0)$ & \\
\hline \multirow[t]{4}{*}{ Koedam scale $^{A-C}$} & 0 & $17(50)$ & 13 (31.7) & 0 & $<0.001$ \\
\hline & 1 & $16(47.1)$ & $22(53.7)$ & $22(73.3)$ & \\
\hline & 2 & $1(2.9)$ & $6(14.6)$ & 7 (23.3) & \\
\hline & 3 & 0 & 0 & $1(3.3)$ & \\
\hline \multirow[t]{2}{*}{ Lobar microbleeds ${ }^{\mathrm{A}, \mathrm{B}}$} & Presence & 0 & $1(2.4)$ & $6(20)$ & 0.002 \\
\hline & Absence & $34(100)$ & $40(97.6)$ & $24(80)$ & \\
\hline
\end{tabular}

SMD, small-vessel disease; MRI, magnetic resonance imaging; NC, normal cognition; MCI, mild cognitive impairment; AD, Alzheimer disease. Post-hoc Bonferroni analysis: ${ }^{A} \mathrm{AD}$ versus $\mathrm{NC}, p<0.05$; ${ }^{\mathrm{B}} \mathrm{AD}$ versus $\mathrm{MCI}$, $p<0.05$; ${ }^{\mathrm{C}} \mathrm{MCI}$ versus NC, $p<0.05$.

\section{Results}

The mean age of subjects was $75.3 \pm 7.9$ years, $68 \%$ were women, and the mean educational level was $8.9 \pm 6.5$ years. Thirty subjects $(28 \%)$ had a probable AD diagnosis, $41(39 \%)$ had MCI, and $34(32 \%)$ had NC. As seen in Table 1, compared to the NC and MCI groups, patients in the probable $\mathrm{AD}$ group were older $(p<0.05)$, had a lower level of education $(p<$ $0.05)$ and a higher frequency of dyslipidemia $(76 \%, p<0.05)$, and were smokers $(76 \%, p<$ $0.05)$. As for cognitive performance, the most severely affected group in all the cognitive domains assessed by the MMSE and the NEUROPSI was the AD group $(p<0.001)$.

Table 2 presents the imaging characteristics of cerebral SVD on MRI findings. According to the $\mathrm{FS}, 8.8,17.3$, and $73 \%$ of $\mathrm{NC}, \mathrm{MCI}$, and probable AD subjects, respectively, were in stage $2(p<0.001)$. According to the SS, $0,2.4$, and $33.3 \%$ of NC, MCI, and probable AD subjects, respectively, were in stage $3(p<0.001)$, and according to the KS, 2.9, 14.6, and $23.3 \%$ of NC, $\mathrm{MCI}$, and probable AD subjects, respectively, were in stage $2(p<0.001)$. Lobar cerebral microbleeds were present in $20 \%$ of probable AD subjects, in $2.4 \%$ of MCI subjects, and in $0 \%$ of NC subjects ( $p=0.002)$.

As seen in Table 3, in the nonadjusted model of the multinomial logistic regression of the FS, SS, and KS scoring results and their association with the presence of MCI and probable AD, we observed an increased risk of probable AD of 16 times (OR $=16,95 \%$ CI 5-47, $p<0.001$ ) and an increase of 2.7-fold in the MCI group (OR $=2.7,95 \%$ CI 1.2-5.8, $p=0.010$ ). After adjusting for possible confounding factors, the risk persisted 7.6-fold using the FS in the probable AD group (OR $=7.6,95 \%$ CI $2.7-20, p<0.001$ ), with a tendency in the MCI group (OR $=2.2,95 \%$ CI $0.90-5.5, p=0.08)$. When using the SS, the risk remained significant for 
Table 3. Unadjusted multinomial regression model and adjustment in patients with MCI and AD (the independent variables analyzed were the Fazekas, Scheltens, and Koedam scales)

\begin{tabular}{|c|c|c|c|c|c|c|c|c|c|}
\hline \multirow[t]{2}{*}{ NC (reference category) } & \multicolumn{3}{|c|}{ Nonadjusted model } & \multicolumn{3}{|c|}{$\begin{array}{l}\text { Model 1: age and } \\
\text { education }\end{array}$} & \multicolumn{3}{|c|}{$\begin{array}{l}\text { Model 2: cardiovascular risk } \\
\text { factors }\end{array}$} \\
\hline & OR & $95 \% \mathrm{CI}$ & $p$ value & OR & $95 \% \mathrm{CI}$ & $p$ value & OR & $95 \%$ CI & $p$ value \\
\hline \multicolumn{10}{|l|}{ Fazekas scale } \\
\hline MCI & 2.7 & $1.2-5.8$ & 0.010 & 2.5 & $1.1-5.7$ & 0.020 & 2.2 & $0.90-5.5$ & 0.08 \\
\hline $\mathrm{AD}$ & 16.1 & $5-47$ & $<0.001$ & 18.0 & $4.8-66$ & $<0.001$ & 7.6 & $2.7-20$ & $<0.001$ \\
\hline \multicolumn{10}{|l|}{ Scheltens scale } \\
\hline MCI & 1.9 & $1.0-3.9$ & 0.05 & 1.8 & $0.90-3.8$ & 0.09 & 1.3 & $0.31-5.5$ & 0.69 \\
\hline $\mathrm{AD}$ & 15.5 & $5.5-43$ & $<0.001$ & 33.0 & $6.6-67$ & $<0.001$ & 4.5 & $3.5-58$ & 0.003 \\
\hline \multicolumn{10}{|l|}{ Koedam scale } \\
\hline MCI & 2.5 & $1.0-5.7$ & 0.03 & 3.0 & $1.1-7.6$ & 0.02 & 0.7 & $0.12-4.3$ & 0.74 \\
\hline $\mathrm{AD}$ & 9.0 & $3.1-25$ & $<0.001$ & 9.1 & $6.1-13$ & $<0.001$ & 8.9 & $1.0-72$ & 0.04 \\
\hline
\end{tabular}

Model 1: adjustment for age and level of education. Model 2: adjustment for diabetes mellitus, hypertension, dyslipidemia, and smoking status. MCI, mild cognitive impairment; AD, Alzheimer disease; NC, normal cognition; OR, odds ratio; CI, confidence interval.

probable $\mathrm{AD}(\mathrm{OR}=4.5,95 \%$ CI 3.5-58, $p=0.003)$ but not for $\mathrm{MCI}(\mathrm{OR}=1.3,95 \%$ CI $0.3-5.5$, $p=0.69)$. Finally, when using the KS, the association with probable AD had an OR of $8.9(95 \%$ CI $1-72, p=0.04)$ and with MCI had an OR of 0.78 (95\% CI 12-4.3, $p=0.74)$.

\section{Discussion}

To our knowledge, there are no studies in Mexican populations that describe the neuroimaging characteristics of SVD. Latin-American countries share high cardiovascular risk profiles, which potentially interact with AD pathology. SVD, which is generally asymptomatic and commonly associated with cardiovascular risk factors, is a prevalent disease in older persons [20,21]. SVD has been found to contribute to up to $45 \%$ of dementias [22].

In this study, the presence of SVD was evaluated with the use of the FS. In addition, we quantified hippocampal and parietal brain atrophy with the SS and the KS, respectively, demonstrating atrophy in participants with $\mathrm{MCI}$ and $\mathrm{AD}$ compared to NC subjects. Temporal atrophy measured with the SS was present in MCI cases and reached the most severe values in probable AD subjects. These findings agree with previous studies $[23,24]$ showing an association between SVD and cortical atrophy regardless of the type of dementia, suggesting that vascular factors could be involved in the pathogenesis of cerebral atrophy in the elderly.

Lobar microbleeds were found in $20 \%$ of probable AD subjects and in $2.4 \%$ of MCI subjects, in agreement with other studies [25, 26]. Recently, an association between microbleeds and cognitive impairment has been suggested, but the mechanisms of this association remain poorly understood [4].

Both MCI and probable AD subjects had a greater prevalence of cardiovascular risk factors compared with NC subjects. Wang et al. [27] have previously demonstrated that the inflammatory, metabolic, and microvascular changes that accompany Western diets, obesity, metabolic syndrome, diabetes, dyslipidemia, and hypertension have important roles in the progression of cognitive impairment, highlighting the strong correlation existing between these factors and the development of SVD. 
Mimenza-Alvarado et al.: Neuroimaging Characteristics of Small-Vessel Disease in Older Adults with Normal Cognition, Mild Cognitive Impairment, and AD

Our findings support the occurrence of important interactions between MCI, SVD, and AD dementia. Erten-Lyons et al. [28] have demonstrated an association between AD pathology and alterations of cerebral white matter integrity. On the same basis, Provenzano et al. [29] previously suggested that the degree of SVD burden could distinguish between patients with NC and AD, with excellent sensitivity and acceptable specificity.

The nonadjusted models showed an association between SVD severity and decreased cognitive performance, which persisted in probable AD subjects after adjusting for age, educational level, and known cardiovascular risk factors with the FS, SS, and KS. Other studies [3032] have previously demonstrated the association between cerebral white matter lesions and reduced cognitive performance, although some results lacked statistical power [1]. In the present study, the association persisted particularly in probable AD subjects, with a tendency in the $\mathrm{MCI}$ group on the FS. Other small studies [33] have also demonstrated low cognitive performance in a small group of elderly patients with SVD.

Our study had some limitations, including its cross-sectional design, which cannot explain the underlying causative mechanisms of cognitive impairment. The calculated convenience sample could affect the study's external validity. Intra- and interobserver reproducibility for brain imaging was not calculated. Future longitudinal studies with larger samples should allow us to better determine the association and potential cause-effect link between SVD and cognition, preferably with the support of histopathology and biomarkers in subjects with AD.

The use of visual scales is useful to evaluate and quantify SVD on MRI. Adequate identification and knowledge of these lesions could allow the establishment of possible measures for their prevention. For these reasons, it is necessary that all specialists involved in the care of patients with dementia identify and classify these vascular lesions quantitatively.

\section{Statement of Ethics}

The research protocol was reviewed and approved by the Institutional Review Board at Instituto Nacional de Ciencias Médicas y Nutrición Salvador Zubiran. All study participants signed an informed consent.

\section{Disclosure Statement}

The authors declare that they have no conflicts of interest and have no sponsor or funding arrangements concerning their research.

\section{References}

1 Mortamais M, Artero S, Ritchie K: White matter hyperintensities as early and independent predictors of Alzheimer's disease risk. J Alzheimers Dis 2014;42(suppl 4):S393-S400.

$\longrightarrow 2$ Bilello M, Doshi J, Nabavizadeh SA, Toledo JB, Erus G, Xie SX, Trojanowski JQ, Han X, Davatzikos C: Correlating cognitive decline with white matter lesion and brain atrophy MRI measurements in Alzheimer's disease. J Alzheimers Dis 2015;48:987-994.

-3 Toledo JB, Arnold SE, Raible K, Brettschneider J, Xie SX, Grossman M, Monsell SE, Kukull WA, Trojanowski JQ: Contribution of cerebrovascular disease in autopsy confirmed neurodegenerative disease cases in the National Alzheimer's Coordinating Centre. Brain 2013;136; 2697-2706.

-4 Wardlaw JM, Smith EE, Biessels GJ, Cordonnier C, Fazekas F, Frayne R, Lindley RI, O’Brien JT, Barkhof F, Benavente OR, Black SE, Brayne C, Breteler M, Chabriat H, DeCarli C, De Leeuw FE, Doubal F, Duering M, Fox NC, Greenberg S, Hachinski V, Kilimann I, Mok V, van Oostenbrugge R, Pantoni L, Speck O, Stephan B, Teipel S, Viswanathan A, Werring D, Chen C, Smith C, van Buchern M, Norrving B, Gorelick PB, Dichgans M: Neuroimaging standards for research into small vessel disease and its contribution to ageing and neurodegeneration. Lancet Neurol 2013;12:822-838. 
5 Fazekas F, Kleinert R, Offenbacher H, Schmidt R, Kleinert G, Payer F, Radner H, Lechner H: Pathologic correlates of incidental MRI white matter signal hyperintensities. Neurology 1993;43:1683-1689.

-6 Scheltens P, Launer LJ, Barkhof F, Weinstein HC, van Gool WA: Visual assessment of medial temporal lobe atrophy on magnetic resonance imaging: interobserver reliability. J Neurol 1995;242:557-560.

7 Koedam EL, Lehmann M, van der Flier WM, Scheltens P, Pijnenburg YA, Fox N, Barkhof F, Wattjes MP: Visual assessment of posterior atrophy development of a MRI rating scale. Eur Radiol 2011;2618-2625.

-8 Warren MW, Weiner MF, Rosetti HC, McColl R, Peshock R, King KS: Cognitive impact of lacunar infarcts and white matter hyperintensity volume. Dement Geriatr Cogn Disord Extra 2015;5:170-175.

$\$ 9$ Benedictus MR, van Harten AC, Leeuwis AE, Koene T, Scheltens P, Barkhof F, Prins ND, van der Flier WM: White matter hyperintensities relate to clinical progression in subjective cognitive decline. Stroke 2015;46:2661-2664.

-10 Folstein MF, Folstein SE, McHugh PR: "Mini-Mental State": a practical method for grading the cognitive state of patients for the clinician. J Psychiatr Res 1975;12:189-198.

11 Morris JC: The Clinical Dementia Rating (CDR): current version and scoring rules. Neurology 1993;43:24122414.

12 Katz S, Ford AB, Moskowitz RW, Jackson BA, Jaffe MW: Studies of illness in the aged. The index of ADL: a standardized measure of biological and psychological function. JAMA 1963;185:914-919.

$\checkmark 13$ Lawton MP, Brody EM: Assessment of older people: self-maintaining and instrumental activities of daily living. Gerontologist 1969;9:179-186.

14 Ostrosky-Solís F, Ardila A, Roselli M: NEUROPSI: a brief neuropsychological test battery in Spanish with norms by age and educational level. J Int Neuropsychol Soc 1999;5:413-433.

15 Petersen RC: Clinical practice. Mild cognitive impairment. N Engl J Med 2011;364:2227-2234.

16 American Psychiatric Association: Diagnostic and Statistical Manual of Mental Disorders, Fourth Edition Text Revision (DSM-IV-TR). Barcelona, Masson, 2002.

17 McKhann GM, Knopman DS, Chertkow H, Hyman BT, Jack CR Jr, Kawas CH, Klunk WE, Koroshetz WJ, Manly JJ, Mayeux R, Mohs RC, Morris JC, Rossor MN, Scheltens P, Carrillo MC, Thies B, Weintraub S, Phelps CH: The diagnosis of dementia due to Alzheimer's disease: recommendations from the National Institute on AgingAlzheimer's Association workgroups on diagnostic guidelines for Alzheimer's disease. Alzheimers Dement 2011;7:263-269.

18 Keefover RW: Aging and cognition. Neurol Clin 1998;16:635-648.

19 Yesavage JA, Brink TL, Rose TL, Lum O, Huang V, Adey M, Leirer VO: Development and validation of a geriatric depression screening scale: a preliminary report. J Psychiatr Res 1982;17:34-37.

20 Mok V, Kim JS: Prevention and management of cerebral small vessel disease. J Stroke 2015;17:111-122.

-21 Kerber KA, Whitman GT, Brown DL, Baloh RW: Increased risk of death in community-dwelling older people with white matter hyperintensities on MRI. J Neurol Sci 2006;250:33-38.

22 Wardlaw JM, Smith C, Dichgans M: Mechanisms underlying sporadic cerebral small vessel disease: insights from neuroimaging. Lancet Neurol 2013, DOI: 10.1016/S1474-4422(13)70060-7.

23 Appelman AP, Exalto LG, van der Graaf Y, Biessels GJ, Mali WP, Geerlings MI: White matter lesions and brain atrophy: more than shared risk factors? A systematic review. Cerebrovasc Dis 2009;28:227-242.

24 Aribisala BS, Valdés Hernández MC, Royle NA, Morris Z, Muñoz Maniega S, Bastin ME, Deary IJ, Wardlaw JM: Brain atrophy associations with white matter lesions in the ageing brain: the Lothian Birth Cohort 1936. Eur Radiol 2013;23:1084-1092.

25 Vernooij MW, van der Lugt A, Ikram MA, Wielpolski PA, Niessen WJ, Hofman A, Krestin GP, Breteler MM: Prevalence and risk factors of cerebral microbleeds: the Rotterdam Scan Study. Neurology 2008;70:1208.

-26 Cordonnier C, Al-Shahi Salman R, Wardlaw J: Spontaneous brain microbleeds: systematic review, subgroup analyses and standards for study design and reporting. Brain 2007;130(Pt 8):1988-2003.

-27 Wang M, Norman JE, Srinivasan VJ, Rutledge JC: Metabolic, inflammatory, and microvascular determinants of white matter disease and cognitive decline. Am J Neurodegener Dis 2016;5:171-177.

28 Erten-Lyons D, Woltjer R, Kaye J, Mattek N, Dodge HH, Green S, Tran H, Howieson DB, Wild K, Silbert LC: Neuropathologic basis of white matter hyperintensity accumulation with advanced age. Neurology 2013;81:977-983.

-29 Provenzano FA, Muraskin J, Tosto G, Narkhede A, Wasserman BT, Griffith EY, Guzman VA, Meier IB, Zimmerman ME, Brickman AM; Alzheimer's Disease Neuroimaging Initiative: White matter hyperintensities and cerebral amyloidosis: necessary and sufficient for clinical expression of Alzheimer disease? JAMA Neurol 2013;70: 455-461.

-30 van der Flier WM, van Straaten EC, Barkhof F, Verdelho A, Madureira S, Pantoni L, Inzitari D, Erkinjuntti T, Crisby M, Waldemar G, Schmidt R, Fazekas F, Scheltens P: Small vessel disease and general cognitive function in nondisabled elderly: the LADIS study. Stroke 2005;36:2116-2120.

-31 Au R, Massaro JM, Wolf PA, Young ME, Beiser A, Seshadri S, D’Agostino RB, DeCarli C: Association of white matter hyperintensity volume with decreased cognitive functioning: the Framingham Heart Study. Arch Neurol 2006;63:246-250.

-32 Mosley TH Jr, Knopman DS, Catellier DJ, Bryan N, Hutchinson RG, Grothues CA, Folsom AR, Cooper LS, Burke GL, Liao D, Szklo M: Cerebral MRI findings and cognitive functioning: the Atherosclerosis Risk in Communities Study. Neurology 2005;64:2056-2062.

-33 Baker JG, Williams AJ, Ionita CC, Lee-Kwen P, Ching M, Miletich RS: Cerebral small vessel disease: cognition, mood, daily functioning, and imaging findings from a small pilot sample. Dement Geriatr Cogn Dis Extra 2012; 2:169-179. 